\title{
Operant rate of planarians as a function of time out from photic stimulation'
}

\section{F. T. CRAWFORD, DEPARTMENT OF PSYCHOLOGY, FLORIDA STATE UNIVERSITY, Tallahassee, Fla. 32306}

Four groups of $10 \mathrm{D}$. dorotocephala were tested over a $1 \mathrm{~h}$ period in a free operant situation. A response of breaking a photobeam provided a time out (TO) from 4 log ft-c for periods of $0,15,30$, and $60 \mathrm{sec}$. The 15- and 30-sec TO groups produced the same mean response rates, which were significantly different from the other two groups. The response rates declined for each of the four groups during successive 15-min periods but was least noticeable for the 15-sec TO.

There have been many studies investigating the responsiveness of planarians to light, and it has been concluded that most planarians are negatively phototactic. Lee (1964) used light as an aversive stimulus in the first report of escape behavior in a free operant situation. Other studies employing essentially the same methodology have been reported by Best (1965) and by Crawford \& Skeen (1967). The present experiment was carried out to determine if the rate at which planarians broke a photobeam, resulting in the turning off of illumination, would vary as a function of the duration of the nonillumination period.

Subjects. The Ss were 40 planarians, Dugesia dorotocephala, divided into four groups of $10 \mathrm{Ss}$ each. Ss were maintained in specimen bowls in which spring water was changed every other day following feeding. Ss were fed black snail meat, which conveniently made the planarians more optically opaque. The animals were housed and the experiment was carried out in a room which was dimly illuminated by a small desk lamp whose shade was placed a few inches above the black surface of a work bench. The temperature of the room was maintained at approximately $22 \mathrm{deg} C$.

Apparatus. The test apparatus consisted of a housing $28 \times 28 \times 42 \mathrm{~cm}$ in width, depth, and height, respectively. The front was hinged for access to a lamp source, a solenoid operated shutter, and heat and light filters located within the housing. On top of the housing was placed a block of clear optical quality plastic, measuring $5.8 \times 5.8 \times 4.0 \mathrm{~cm}$ in width, depth, and height, respectively. A hole in the top of the housing was cut so that light from the lamp source in the bottom was projected through the plastic block. The housing was painted flat black and was placed upon cushioning to absorb vibration.

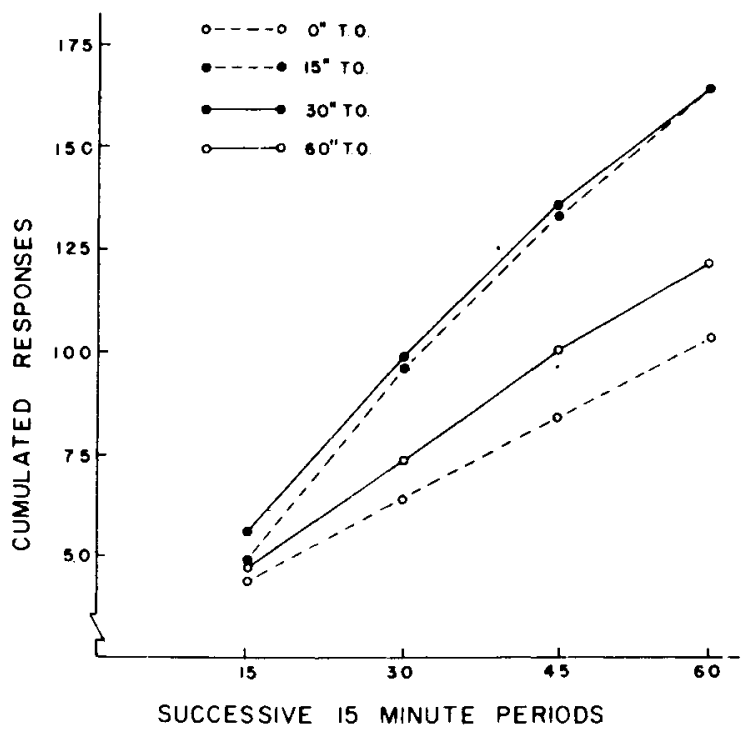

Fig. 1. Cummulated responses for the four time out groups over successive 15 min periods.

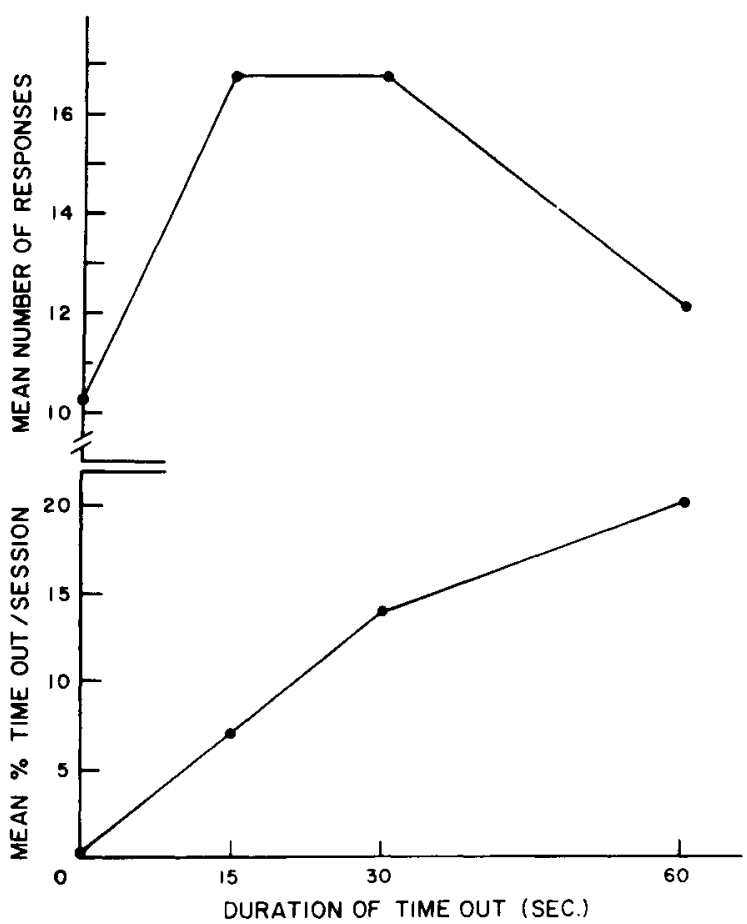

Fig. 2. Mean number of responses and mean per cent time out as a function of time out duration.

Two chambers, $1.90 \mathrm{~cm}$ in diameter and $1.27 \mathrm{~cm}$ deep, were milled out of the block of plastic. The inner circumferences of the test chambers were separated by $.64 \mathrm{~cm}$. A glass-clad light-conducting plastic rod, $.32 \mathrm{~cm}$ in diameter, was located at the outside diameter of each test chamber. The light-conducting rod was positioned $.32 \mathrm{~cm}$ above the floor of each test chamber. Each light-conducting rod rose vertically from the test chamber, was bent at a right angle, and positioned into a tunnel through a block of aluminum. The aluminum block was mounted on top of the test housing on adjustable springs. The springs were adjusted so that the light-conducting rod could be properly positioned in the test chamber. A photocell was fitted into an enlargement of the other end of the tunnel in the aluminum block.

A $22.86 \mathrm{~cm}^{2}$ pyrex baking dish containing $2.54 \mathrm{~cm}$ water was used as a heat filter. Four sheets of onion skin paper were used to diffuse and reduce the level of illumination to $0.4 \mathrm{ft}-\mathrm{c}$. The apparatus included relay control panels, a clock, counters, and recorders. When a $S$ would move beneath the light-conducting rod, thus breaking the beam to the photocell, a clock would time the duration that the shutter would remain closed.

Procedure. In the present study only the left test chamber was used. Each $S$ in each of the four groups was tested over a $1 \mathrm{~h}$ period. For each of the four groups the breaking of the photobeam by the $S$ closed the shutter, and thus turned off the light, for $0,15,30$, and $60 \mathrm{sec}$.

Results and Discussion. The cummulated responses for the four groups are shown for successive 15 -min periods in Fig. I. The 0-sec time out (TO) produced the lowest rate of response. The 60-sec TO did not result in a significantly higher response rate than that of the $0-\sec$ TO $\left(t_{0,60}=1.77,18 \mathrm{df}\right)$. The 15 -sec and 30 -sec To resulted in essentially equal response rates in their groups, both of which were significantly different from the 60-sec TO (e.g., $\mathrm{t}_{15.60}=3.19,18 \mathrm{df}$ ).

Figure 2 shows the mean number of total responses made by each of the TO groups. The 15-and 30-sec TO groups both made a mean 16.8 responses. The mean per cent $\mathrm{TO} /$ session for each of 


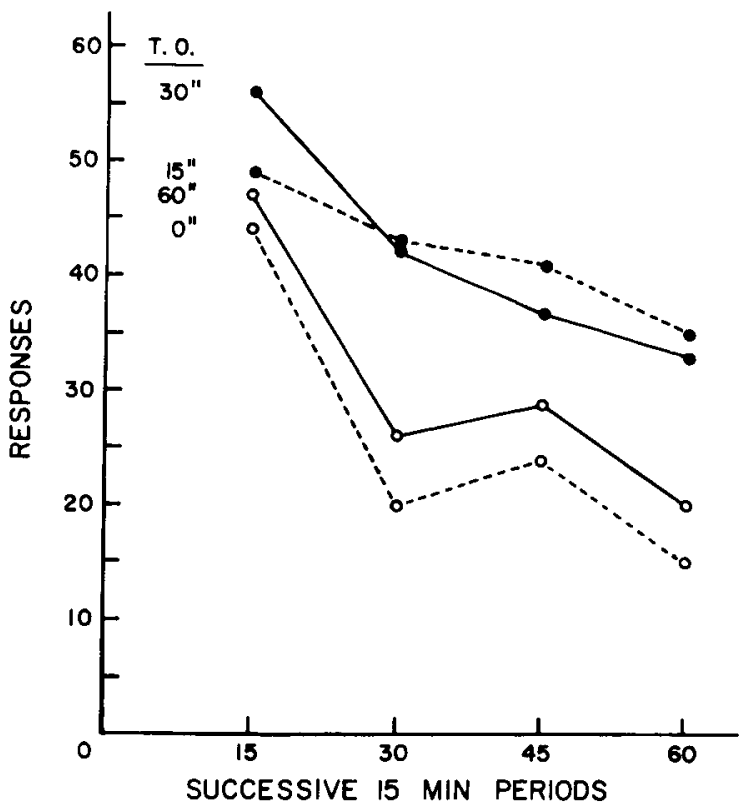

Fig. 3. Number of responses made by the four time out groups during successive $15 \mathrm{~min}$ periods.

the TO periods is also shown in Fig. 2. The mean per cent $\mathrm{TO} /$ session is the percentage of the total 60 -min test period that the lamp source was turned off. Thus, the figure shows that the $60-\mathrm{sec}$ TO group terminated the illumination $20.3 \%$ of the time or a total of $12.2 \mathrm{~min}$. The regularity of this function would make it appear that the planarians demonstrate a certain amount of "efficiency" in adjusting their total amount of illumination.

A previous study on the operant behavior of planarians (Crawford \& Skeen, 1967) had reported comparable cummulated response curves over a $4 \mathrm{~h}$ training period. In that study, an examination of the number of responses made during each successive $1 / 2 \mathrm{~h}$ period showed an initial increase in response rate followed by a response decrement during the later $1 / 2 \mathrm{~h}$ training periods. In a similar manner, the data of the present experiment for successive $15-\mathrm{min}$ periods is shown in Fig. 3. Unlike the preceding experiment, the response rates for all four groups fell off from the beginning, although the rate of decline was less in the 15-sec TO group. A similar decline in response rate was mentioned by Lee (1963). An examination of the data reported by Best (1965) also indicates the same diminution in response rate. The effect has been reported in maze learning by Best \& Rubinstein (1962) who suggest that such effects are not necessarily due to fatigue. Similar findings have been reported in a variety of other invertebrate animal learning preparations. The effect has been described or attributed to lethargy, adaptation, fatigue, habituation, or moribundity.

The planarians of the present study were used for a biochemical analysis immediately after being run in the experiment. In other unpublished studies, using similar procedures, removal from the apparatus typically results in renewed activity in the planarian. It appears that habituation is operating, and not moribundity.

\section{REFERENCES}

BEST, J. B. Behavior of planaria in instrumental learning paradigms. Anim Behav. Suppl. 1, 1965, 13, 69-75.

BEST, J. B., \& RUBINSTEIN, I. Maze learning and associated behavior in planaria. J. comp. physiol Psychol., 1962, 55, 560-566.

CRAWFORD, F. T., \& SKEEN, L. C. Operant responding in the planarian: a replication study. Psychol. Rep., 1967, 20, 1023-1027.

LEE, R. M. Conditioning of a free operant in planaria. Science, 1963, 139, 1045-1049.

\section{NOTE}

1. This study was carried out in the Molecular Psychobiology Laboratory at York University, Toronto, Ontario, Canada. It was supported in part by a Summer Grant-In-Aid from the Florida State University; and by the Office of Naval Research Contract Nonr 495(00) and Grant No. APB-122 from the National Research Council of Canada. 